\title{
Nanoscale Precipitation Coating: The Deposition of Inorganic Films through Step-by-Step Spray-Assembly
}

\author{
Gabriela Popa, ${ }^{\dagger}$ Fouzia Boulmedais, ${ }^{\dagger}$ Peng Zhao, ${ }^{+, q}$ Joseph Hemmerlé, ${ }^{\neq, \S}$ Loïc Vidal, ${ }^{\perp}$ Eric Mathieu, ${ }^{\neq, \S}$ \\ Olivier Félix, ${ }^{+}$Pierre Schaaf, ${ }^{+, \|}$Gero Decher, ${ }^{+, \#, \|, \nabla, *}$ and Jean-Claude Voegel ${ }^{\ddagger, \delta, *}$ \\ ${ }^{\dagger}$ Centre National de la Recherche Scientifique, Institut Charles Sadron (ICS), UPR 22, 23 rue Loess 67083 Strasbourg, France, ${ }^{\ddagger}$ Institut National de la Santé et de la \\ Recherche Médicale, UMR 977, 11 rue Humann, 67085 Strasbourg, France, ${ }^{\S}$ Faculté de Chirurgie Dentaire, Université de Strasbourg, 1 place de l'Hôpital 67000 \\ Strasbourg, France, ${ }^{\perp}$ Institut de Science des Matériaux de Mulhouse (IS2M) - CNRS LRC 7228, 15 rue Jean Starcky, BP 2488, 68057 Mulhouse Cedex, France, " Faculté de \\ Chimie, Université de Strasbourg, 1 rue Blaise Pascal 67008, Strasbourg, France, "International Center for Frontier Research in Chemistry, 8 allée Gaspard Monge, 67083 \\ Strasbourg, France, and ${ }^{\nabla}$ Institut Universitaire de France, 103 Boulevard Saint-Michel, 75005 Paris, France. "Present address: The Institute for Advanced Materials and \\ Nano Biomedicine, Tongji University, 1239 Siping Road, Shanghai, 200092, China.
}

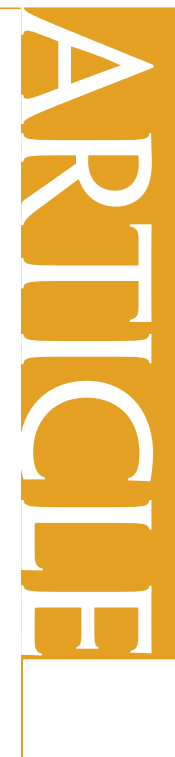

$\mathrm{T}$ hin films and functional surfaces constitute an important field in materials science ${ }^{1-10}$ with applications in areas such as device engineering, corrosion protection, antistatic coatings, photovoltaics, or biosensing, to name a few. The last decades have brought the evolution of film deposition methods involving transfer through the gas phase such as physical vapor deposition (PVD), chemical vapor deposition (CVD), sputtering, and some variants. However, vacuum-based techniques are somewhat hampered because conformal coatings are often limited to small surface areas on smooth objects, because they are more difficult to integrate in production processes than solution based techniques, because they are often time-consuming and costly, or because it is highly desirable to improve the sustainability benchmarks of the corresponding products. Consequently, solvent based methods such as surface ${ }^{11,12}$ or more recently nanometric ${ }^{13}$ or spray pyrolysis ${ }^{14}$ have increasingly been investigated for the fabrication of inorganic coatings. A particularly interesting technique for producing a large variety of different inorganic films is the step-by-step dipping method or SILAR (successive ionic layer adsorption and reaction) first reported by Nicolau in $1984 . .^{15-17}$ A major advantage of the SILAR method over surface sol-gel technology is that inorganic films composed of a much wider range of inorganic components can be prepared using a single process.

One aspect of the SILAR method, the consecutive immersion of surfaces in differ-
ABSTRACT Thin films and surface coatings play an important role in basic and applied research. Here we report on a new, versatile, and simple method ("precipitation coating") for the preparation of inorganic films, based on the alternate spraying of complementary inorganic salt solutions against a receiving surface on which the inorganic deposit forms. The method applies whenever the solubility of the deposited material is smaller than that of the salts in the solutions of the reactants. The film thickness is controlled from nanometers to hundreds of micrometers simply by varying the number of spraying steps; 200 spray cycles, corresponding to less than $15 \mathrm{~min}$ deposition time, yield films with thicknesses exceeding one micrometer and reaching tens of micrometers in some cases. The new solution-based process is also compatible with conventional layer-by-layer assembly and permits the fabrication of multimaterial sandwich-like coatings.

KEYWORDS: inorganic coatings - spray assembly $\cdot$ aqueous solutions $\cdot$ nucleation and growth $\cdot$ thin films

ent liquids, is somewhat similar to the wellknown layer-by-layer (LbL) ${ }^{4,18,19}$ deposition of organic, polymeric, or hybrid thin films that has become attractive because of a wealth of different functionalities available for incorporation in such nanometric coatings. ${ }^{20-27}$ Both SILAR and LbL methods allow the construction of nanometer-sized coatings with precise thickness, but they both suffer from the same drawback, namely that the immersion of an object in a liquid and its subsequent withdrawal, especially if carried out hundreds of times in different solutions, is a time-consuming process and therefore limited to the coating of small and simply shaped objects from which the adhering liquid easily drains. Not surprisingly, multistep dipping-based methods are difficult to implement in industrial production with the possible exception of roll-to-roll processes. Inevitably, the LbLassembly of thin multimaterial films has

\author{
*Address correspondence to \\ Jean-Claude.Voegel@ \\ medecine.u-strasbg.fr, \\ decher@ics.u-strasbg.fr. \\ Received for review March 18, 2010 \\ and accepted July 02, 2010. \\ Published online Xxxxxxxxx 00, 0000 \\ $10.1021 / \mathrm{nn} 1005667$ \\ () XXXX American Chemical Society
}




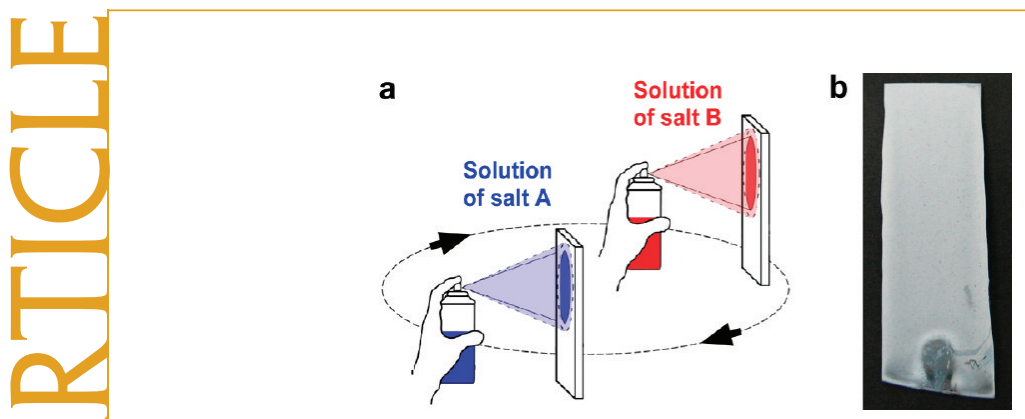

Figure 1. (a) Schematic depiction of the deposition of purely inorganic films $A B$ from aqueous solutions by consecutively spraying solutions of the complementary salts $A$ and $B$ onto a receiving solid surface. (b) Optical micrograph of a film of calcium phosphate after 75 spray cycles deposited on a silicon wafer of a size of $1.5 \times 5.0 \mathrm{~cm}$. Due to its polycrystallinity and nanoporous morphology the film appears white in reflected light. Besides a mark at the bottom that originates from mounting the wafer, the film is macroscopically very homogeneous.

gained enormously from the introduction of sprayassisted deposition as reported by, for example, Schlenoff, ${ }^{28}$ Winterton, ${ }^{29}$ Izquierdo, ${ }^{30}$ Kotov, ${ }^{31}$ or Hammond. ${ }^{32}$ LbL-films assembled by spray deposition can often be prepared in a fraction of the time as compared to deposition by dipping and often possess a superior homogeneity sometimes in combination with improved materials properties.

The nanoscale "precipitation coating" technique that we introduce here is based on the step-by-step spraying of solutions of complementary salts (Figure 1a) that possess a non-negligible difference of the solubility products compared to that of the solid inorganic product that forms a film on the receiving surface by precipitation due to a local supersaturation.

It is as versatile for the preparation of inorganic coatings as the SILAR method, but it is very fast and has the additional advantage that spray technology is widely accepted in industrial production. In contrast to sprayLbL which is mostly used for the assembly of polyelectrolyte and related multilayer films, it is more difficult to prevent small salt ions (such as $\mathrm{Ca}^{2+}, \mathrm{F}^{-}, \mathrm{Cl}^{-}, \mathrm{H}_{2} \mathrm{PO}_{4}{ }^{-}$l $\mathrm{HPO}_{4}{ }^{2-}$ ) adsorbed on a surface in the previous deposition step or even nanocrystals from being washed off under the shear of the sprayed solution in the next adsorption step. It actually turns out that the subsequent removal or dissolution of previously adsorbed material is a critical factor that must, in some cases, be controlled for growing high quality films. The very short contact times of the complementary liquids attainable only by spraying against a receiving surface can clearly be shown, for example, in the case of $\mathrm{CaHPO}_{4}$, to be essential for precisely controlling the film growth over hundreds of spray cycles.

The consecutive spray application of solution $A$ and solution $B$ can be repeated hundreds of times in a few minutes to increase the thickness of the inorganic coating until a film with the desired thickness (from a few nanometers up to several micrometers or more) is obtained. It should be clear that these inorganic coatings

do not possess a multilayer structure as in the case of classic polyelectrolyte multilayer films; however, they are fabricated in the same way by employing the stepby-step assembly method as adapted to spray deposition. The following complementary salt pairs (for solubility data see Table S1 in Supporting Information) were chosen as model cases for demonstrating the fabrication of inorganic films by step-by-step spraying: (i) $\mathrm{CaCl}_{2}$ and $\mathrm{NaF}$ which yields calcium fluoride $\left(\mathrm{CaF}_{2}\right)$ possessing a high UV transparency which makes it interesting for applications in optical components such as lenses, prisms or windows and because it forms very dense and rather smooth inorganic films. (ii) $\mathrm{CaCl}_{2}$ and $\left(\mathrm{NH}_{4}\right)_{2} \mathrm{HPO}_{4}$ which yields calcium phosphate $\left(\mathrm{CaHPO}_{4}\right)$, a material that has wide ranging applications in the biomedical field, for example for bone reconstruction. (iii) $\mathrm{Ca}\left(\mathrm{NO}_{3}\right)_{2}$ and $\mathrm{Na}_{2} \mathrm{C}_{2} \mathrm{O}_{4}$ which yields calcium oxalate $\left(\mathrm{CaC}_{2} \mathrm{O}_{4}\right)$ serving as an example for the use of a carbon-based anion.

\section{RESULTS AND DISCUSSION}

Preparation of Inorganic Films by Spray Deposition. The spray-assembly of inorganic films - a typical sample is shown in Figure 1b-was carried out by using conventional air pump spray cans equipped with singlecomponent nozzles. We refer to a spraying cycle $(A / B)_{1}$ as a process consisting of the spraying of a component A for about $2 \mathrm{~s}$ followed by spraying of a component $\mathrm{B}$ for about $2 \mathrm{~s}$. The desired spray cycles can be repeated $n$ times to form $(A / B)_{n}$ films. Prior to the deposition of the inorganic films the receiving surface was coated with at least one polyelectrolyte layer to promote its adhesion, in some cases the receiving surface was coated with a LBL-film of collagen and poly(styrene sulfonate) (COL/PSS) ${ }_{8}$ with a thickness of about $10 \mathrm{~nm}$ because the combination of calcium phosphate with collagen has a certain interest for the reconstruction of bone or cartilage. However, the deposition of inorganic films does not require the presence of collagen in the layer underneath, and similar films can be prepared on many other types of surfaces.

While the first spraying step only leads to the formation of a thin liquid film of solution $A$, the subsequent spraying step of solution B "into" the draining film of solution $A$ leads to a reaction between both complementary salt solutions. If the solutions of the two complementary starting materials (e.g., $\mathrm{CaCl}_{2}$ and $\mathrm{NaF}$ ) are chosen such that the resulting reaction product (in this case $\mathrm{CaF}_{2}$ ) becomes supersaturated in the liquid film close to the surface of the solid, nucleation will start and germs close to the surface will, depending on the chemical nature of the surface, attach to it. However, since solution B was sprayed last it will, depending on the sprayed volume, now be in excess and the subsequent spray application of solution A will again produce a supersaturated solution of the reaction product (in this case $\left(\mathrm{CFF}_{2}\right)$. Starting with the third spray application, nucleation is either starting as before or induced 


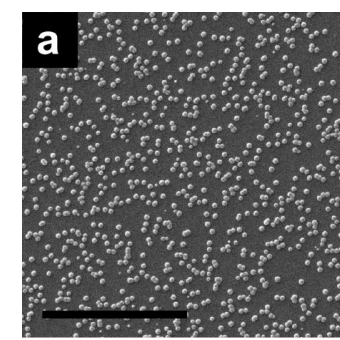

e

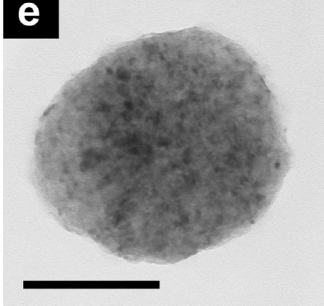

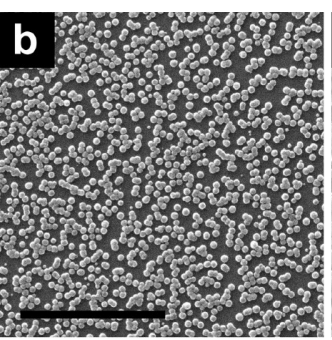

$\mathbf{f}$

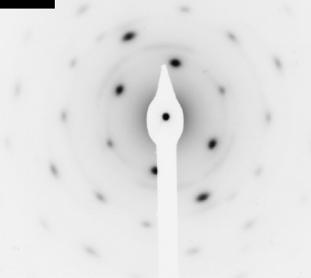

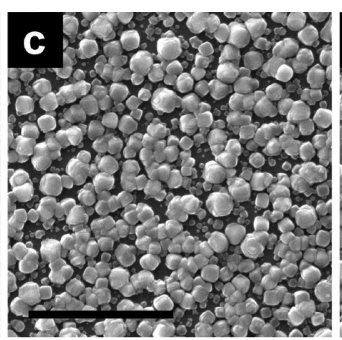

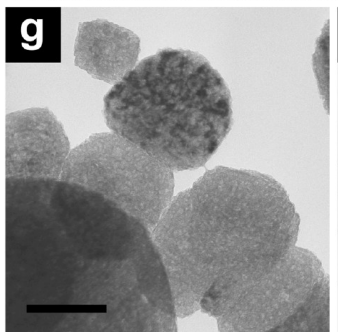

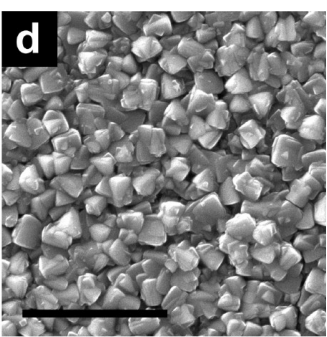

$\mathbf{h}$

Figure 2. Top view scanning electron micrographs of films composed of $\mathrm{CaF}_{2}(\mathrm{a}-\mathrm{d})$ at various stages of film growth. The numbers of spray cycles for each sample are as follows: 3 (a), 10 (b), 50 (c) and 200 (d). The scale bar represents $10 \mu \mathrm{m}$. Electron micrographs and diffraction patterns were obtained by transmission electron microscopy from $\mathrm{CaF}_{2} \mathrm{crystals}$ after one cycle $(e, f)$ and three cycles $(g, h)$. Scale bars represent $100 \mathrm{~nm}$ for image e and $200 \mathrm{~nm}$ for image $\mathrm{g}$.

by crystals already attached to the surface thus accelerating the growth of the inorganic film.

Films of all different materials were spray-assembled up to a given thickness by adjusting the number of deposition cycles, dried in a stream of air or nitrogen, and then characterized. The chemical composition and crystalline phase of the components were determined by electron and X-ray diffraction by comparison with known data (see Tables S2-S4 and Figure S1 in Supporting Information). The alternate spraying of $\mathrm{CaCl}_{2}$ and $\mathrm{NaF}$ yields fluorine films $\left(\mathrm{CaF}_{2}\right)$, the spraying of $\mathrm{Ca}\left(\mathrm{NO}_{3}\right)_{2}$ and $\left(\mathrm{NH}_{4}\right)_{2} \mathrm{HPO}_{4}$ yields calcium phosphate films (brushite, $\mathrm{CaHPO}_{4}$ ), and the spraying of $\mathrm{CaCl}_{2}$ and $\mathrm{Na}_{2} \mathrm{C}_{2} \mathrm{O}_{4}$ yields calcium oxalate films $\left(\mathrm{CaC}_{2} \mathrm{O}_{4}\right)$.

Dense Polycrystalline Films: Spray Deposition of Calcium Fluoride Films. For $\mathrm{CaF}_{2}$, scanning electron microscopy (SEM) revealed that the film growth starts by the forma- tion of nanocrystals with a very small lateral density (Figure 2a). By increasing the number of spray cycles, the size and density of crystals increases until most voids are filled and layer growth proceeds predominantly along the layer normal (Figure $2 \mathrm{a}-\mathrm{d}$ ). Transmission electron microscopy (TEM) and electron diffraction show that in the case of $\mathrm{CaF}_{2}$ the smallest observable crystals (about $70 \mathrm{~nm}$ ) are monocrystalline (Figure 2e,f) which further increase in size (Figure $2 b-d$ ) and become polycrystalline (Figure $2 \mathrm{~g}, \mathrm{~h}$ ).

Porous Polycrystalline Films: Spray Deposition of Calcium Phosphate and 0xalate Films. In the case of $\mathrm{CaHPO}_{4}$, the film growth proceeds by nucleation of additional small crystals rather than by crystal growth (Figure $3 a-d$ ) which also leads to more porous film morphology. In contrast to $\mathrm{CaF}_{2}$, even the smallest crystals are polycrystalline (Figure $3 e, f$ ) as evidenced by the circular diffrac-

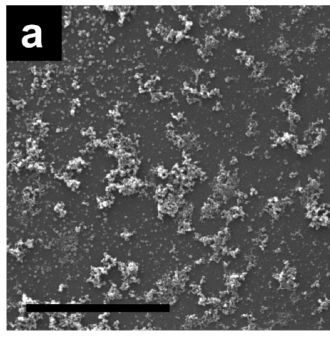

e

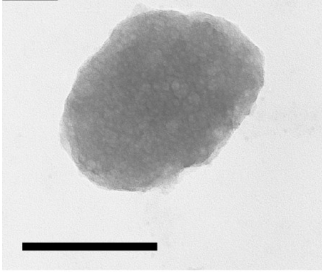

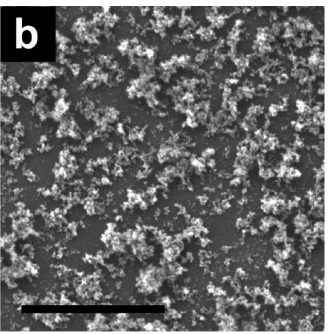

f

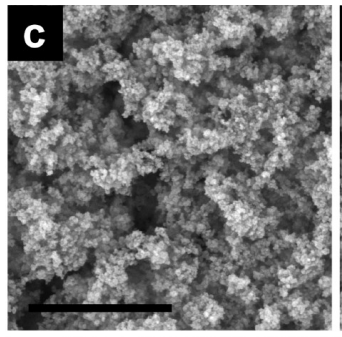

g

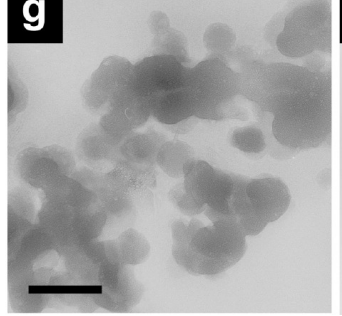

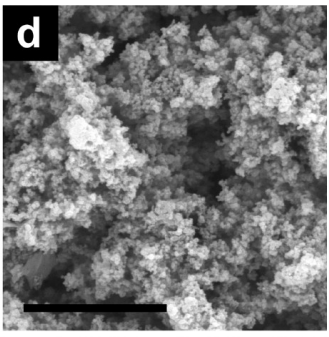

h

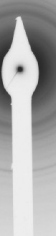

Figure 3. Top view scanning electron micrographs of films composed of $\mathrm{CaHPO}_{4}(\mathrm{a}-\mathrm{d})$ at various stages of film growth. The numbers of spray cycles for each sample are as follows: 3 (a), 10 (b), 50 (c) and 200 (d). The scale bar represents $10 \mu \mathrm{m}$. Electron micrographs and diffraction patterns were obtained by transmission electron microscopy from $\mathrm{CaHPO}_{4} \mathrm{Crystals}$ after one cycle $(e, f)$ and three cycles $(g, h)$. Scale bars represent $100 \mathrm{~nm}$ for image e and $200 \mathrm{~nm}$ for images $\mathrm{g}$. 

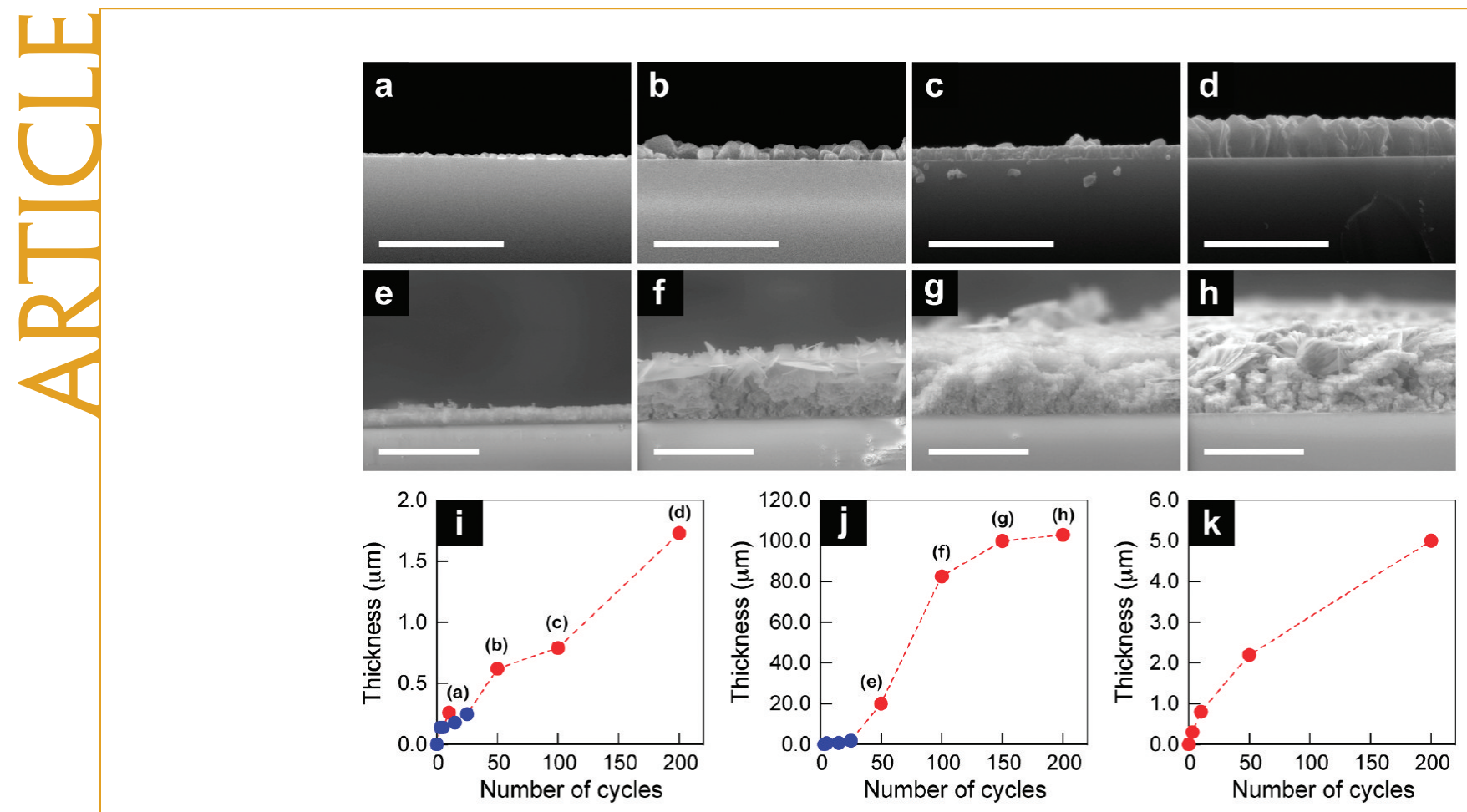

Figure 4. Side-view scanning electron micrographs of films composed of $\mathrm{CaF}_{2}(\mathrm{a}-\mathrm{d})$ and $\mathrm{CaHPO}_{4}(\mathrm{e}-\mathrm{h})$ at various stages of film growth. Evolution of the thickness of (i) $\mathrm{CaF}_{2}$, (j) $\mathrm{CaHPO}_{4}$, and (k) $\mathrm{CaC}_{2} \mathrm{O}_{4}$ films versus the number of spraying cycles. Thicknesses were determined either by AFM (scratch of the coating: blue circles) and SEM side-view (red circles). The numbers of spray cycles for each sample are as follows: $10(\mathrm{a}), 50(\mathrm{~b}, \mathrm{e}), 100(\mathrm{c}, \mathrm{f}), 150(\mathrm{~g})$, and $200(\mathrm{~d}, \mathrm{~g})$. The scale bars represent $5 \mu \mathrm{m}$ for $(a-d)$ and $100 \mu \mathrm{m}$ for $(e-h)$. Dotted lines are guides.

tion pattern. Please note that the high magnification in Figure $3 d$ leaves the impression of a rather irregular film morphology. However, Figure $1 \mathrm{~b}$ and Figure S2 clearly underlines the good film homogeneity at a larger scale. The same porous morphology of $\mathrm{CaC}_{2} \mathrm{O}_{4}$ films was observed (see Figure S3 in Supporting Information).

Analysis of Film Growth. Because of the large range of attainable film thicknesses to the solution-based deposition and to the polycrystalline and porous nature of the films, it was impossible to characterize the film thickness by some of the usual methods such as ellipsometry or quartz crystal microbalance. Film thicknesses were therefore determined by AFM (below $200 \mathrm{~nm}$ ) and SEM (up to the $100 \mu \mathrm{m}$ range) (Figure 4) and also estimated by UV-vis spectrophotometry (Figure 5).

From left to right in the case of $\mathrm{CaF}_{2}$ (Figure $4 a-d$ ) and $\mathrm{CaHPO}_{4}$ (Figure $4 \mathrm{e}-\mathrm{h}$ ), one clearly observes the increasing film thickness with an increasing number of spray cycles. In all cases presently investigated, films reached a thickness above $1 \mu \mathrm{m}$ after 200 spray cycles (Figure $4 \mathrm{i}-\mathrm{k}$ ). In the case of $\mathrm{CaHPO}_{4}$ a thickness of about $1 \mu \mathrm{m}$ is reached after a few spray cycles and film growth leveled off at a thickness of about $100 \mu \mathrm{m}$. All three cases show that the thickness of the inorganic films is controlled by the number of spray cycles.

Factors Controlling Film Growth. Depending on the exact chemical composition of each pair of complementary salts, a second control mechanism becomes important: the control of contact times and thus the speed by which one solution can be replaced by the following complementary one. As we show in Figure 5 the spraying time has a strong influence on the buildup of inorganic films. While in the case of $\mathrm{CaF}_{2}$ (Figure 5a) a spraying time of $2 \mathrm{~s}$ leads to films with twice the absorbance (corresponding approximately to twice the thickness) as compared to films sprayed for $1 \mathrm{~s}$, the thickness of films of $\mathrm{CaC}_{2} \mathrm{O}_{4}$ are almost independent of spraying
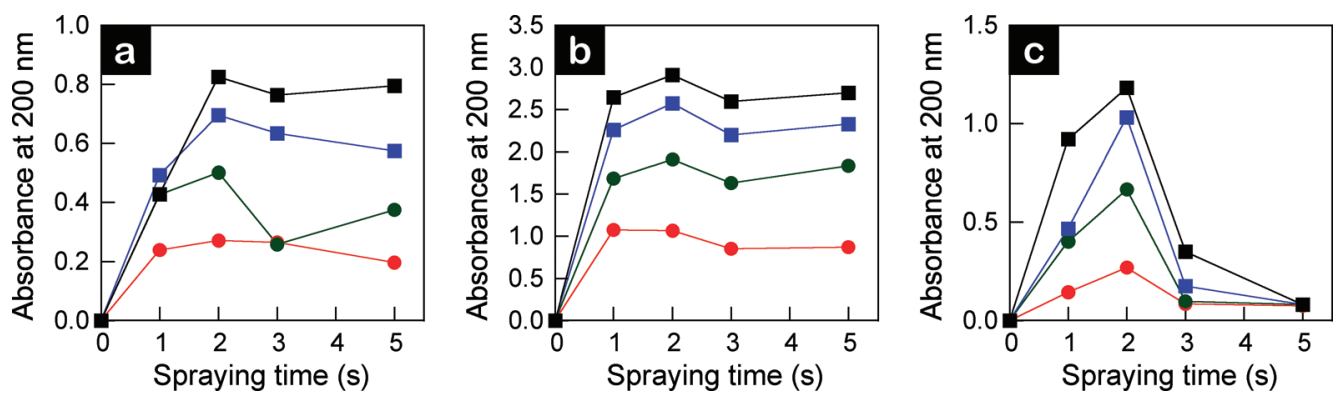

Figure 5. Evolution of the absorbance measured by $\mathrm{UV}$ at $200 \mathrm{~nm}$ versus spraying time of (a) $\mathrm{CaF}_{2}$, (b) $\mathrm{CaC}_{2} \mathrm{O}_{4}$, and (c) $\mathrm{CaH}-$ $\mathrm{PO}_{4}$ coatings after 5 (red), 10 (green), 15 (blue), and 20 (black) cycles. Solid lines are guides. 
times above $1 \mathrm{~s}$ (Figure 5b). $\mathrm{CaHPO}_{4}$ films even start to redissolve at spraying times longer than $2 \mathrm{~s}$ (Figure $5 \mathrm{c}$ ).

It is evident that in cases in which a fast switching between complementary solutions is required to prevent the redissolution of the film, spraying is the sole method applicable to create such coatings, since the whole surface of a substrate can almost simultaneously be exposed to the spray cone from the third dimension. In contrast, the immersion of a substrate into a liquid always leads to a distribution of contact times along the dipping direction except for a roll-to-roll process, which can only be used with foils and similar soft substrates. The observed redissolution of some inorganic films at longer contact times (Figure $5 c$ ) may be due to two different phenomena, the effects of each of which can equally and effectively be reduced at short spraying times. For films of inorganic salts composed of weakly adhering crystals, the draining liquid exercises a sufficient drag for removing poorly sticking crystals mechanically. For films in which the final inorganic product is partially soluble in one of the two solutions of the complementary starting materials, previously formed crystals can also partly or completely be redissolved.

Toward Multimaterial and Sandwich Films. The "precipitation coating" technique described above is also compatible with the classic LbL-assembly of polyelectrolytes and can be used for the fabrication of multimaterial sandwich films. Figure 6 shows profiling information obtained by confocal Raman microspectroscopy along the layer normal of a film prepared by 100 spray cycles of calcium oxalate followed by 100 spray cycles of calcium fluoride.

Despite of the limited spatial resolution it is evident that the film is rich in calcium oxalate at the bottom

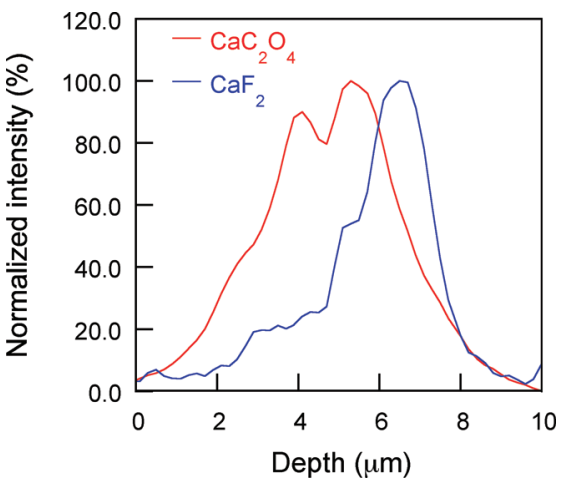

Figure 6. Depth profile for a PEI- $\left(\mathrm{CaC}_{2} \mathrm{O}_{4}\right)_{100}$-(PSS/PAH) $)_{5}^{-}$ $\left(\mathrm{CaF}_{2}\right)_{100}$ hybrid film visualized as the intensities of the Raman bands of calcium oxalate (red line) at $1478 \mathrm{~cm}^{-1}$ and calcium fluoride (blue line) at $312 \mathrm{~cm}^{-1}$ as obtained by confocal Raman microspectroscopy. For each band, the intensity was normalized by attributing the value $100 \%$ to the maximum intensity.

and rich in calcium fluoride at the top. Because of its versatility and simplicity, we anticipate the "precipitation coating" technique to become a method of wide use for the preparation of inorganic nanoscale coatings. At the present time we have not yet optimized the materials properties of our new films with respect to evaluating their potential for application in devices. However, we do believe that our step-by-step spray process could become relevant for some applications because it does not seem to depend much on the shape and size of the receiving surface. Further, our method opens the possibility to fabricate films of hybrid precipitates by spraying more than one complementary component in each spraying step.

\section{METHODS}

Materials. Collagen (COL, batch: 07CBPE2040) was purchased from SYMATESE (Grenoble, France). Poly(ethylene imine) (PEI, $\left.\bar{M}_{\mathrm{w}}=700000 \mathrm{~g} / \mathrm{mol}\right)$, poly(styrene sulfonate) (PSS, $\bar{M}_{\mathrm{w}}=70000$ $\mathrm{g} / \mathrm{mol})$, calcium nitrate $\left(\mathrm{Ca}\left(\mathrm{NO}_{3}\right)_{2}, 4 \mathrm{H}_{2} \mathrm{O}\right)$ and Trizma hydrochloride (T32253) were purchased from Sigma Aldrich. Sodium acetate $\left(\mathrm{CH}_{3} \mathrm{COONa}\right.$, aqueous $3 \mathrm{M}$ solution), diammonium hydrogen phosphate $\left(\left(\mathrm{NH}_{4}\right)_{2} \mathrm{HPO}_{4}\right)$, sodium fluoride $(\mathrm{NaF})$, and sodium oxalate $\left(\mathrm{Na}_{2} \mathrm{C}_{2} \mathrm{O}_{4}\right)$ were purchased from Fluka. Calcium chloride $\left(\mathrm{CaCl}_{2} \cdot 2 \mathrm{H}_{2} \mathrm{O}\right)$ and acetic acid $\left(\mathrm{CH}_{3} \mathrm{COOH}\right)$ were respectively purchased from Carlo Erba Reagents and VWR Prolabo. All the products were used without further purification. The salt solutions were prepared in ultrapure water (Milli-Q Gradient System, Millipore) with a resistivity of $18.2 \mathrm{M} \Omega \cdot \mathrm{cm}$. PEl solutions were prepared at a concentration of $2.5 \mathrm{mg} / \mathrm{mL}$ in Milli-Q water. One liter of acetate buffer $(\mathrm{pH}=4)$ was prepared from acetic acid (8.1 $\mathrm{mM})$, sodium acetate $(1.8 \mathrm{mM})$, and $\mathrm{NaCl}(154 \mathrm{mM})$. COL solutions were prepared at a concentration of $0.2 \mathrm{mg} / \mathrm{mL}$ in acetate buffer at $\mathrm{pH} 4$ where it is positively charged. PSS solutions were prepared at a concentration of $1 \mathrm{mg} / \mathrm{mL}$ in $0.15 \mathrm{M} \mathrm{NaCl}$ at pH 6.5 . For calcium phosphate $\left(\mathrm{CaHPO}_{4}\right)$ synthesis, a calcium solution of $\mathrm{Ca}\left(\mathrm{NO}_{3}\right)_{2} \cdot 4 \mathrm{H}_{2} \mathrm{O}(0.32 \mathrm{M})$ and a phosphate solution of $\left(\mathrm{NH}_{4}\right)_{2} \mathrm{HPO}_{4}(0.19 \mathrm{M})$ were prepared in Tris buffer (10 mM Trizma, $\mathrm{pH}=10)$. Calcium fluoride $\left(\mathrm{CaF}_{2}\right)$ was synthesized from a solution of $\mathrm{CaCl}_{2}\left(2 \times 10^{-2} \mathrm{M}\right)$ and $\mathrm{NaF}\left(2 \times 10^{-2} \mathrm{M}\right)$ prepared in Milli-Q water. Calcium oxalate $\left(\mathrm{CaC}_{2} \mathrm{O}_{4}\right)$ was prepared using
$\mathrm{NaC}_{2} \mathrm{O}_{4}\left(10^{-1} \mathrm{M}\right)$ and $\mathrm{CaCl}_{2}\left(2 \times 10^{-1} \mathrm{M}\right)$ prepared in Milli-Q water.

Inorganic Spray Assembly. The spray deposition was carried out by using air pump spray cans ("Air Boy") made of polypropylene and polyethylene purchased from Roth (reference number: 0110.1) with a height of $217 \mathrm{~mm}$ and a diameter of $55 \mathrm{~mm}$; equipped with a nozzle of $0.40 \mathrm{~mm}$ ). Each can was filled with the respective salt solution and then pressurized by pumping cycles in such a way that the spray rate remained approximately constant over the entire film deposition process. The spray rate was determined to be about $0.6 \mathrm{~mL} / \mathrm{s}$ with pump flasks as they were received from the manufacturer. Spraying was carried out perpendicularly to the receiving surface which was fixed in a vertical orientation. Inorganic salt solutions were alternately sprayed for $2 \mathrm{~s}$ unless otherwise stated until the desired number of cycles. After a rest time of $60 \mathrm{~s}$, a rinsing step with Milli-Q-water of $5 \times$ $1 \mathrm{~s}$ using the spraying bottles was applied to the inorganic film.

LBL-Multilayer Films. All the films were built on glass slides of $12 \mathrm{~mm}$ diameter (VWR, Fontenay sous Bois, France), silicon wafers (100) (Wafernet, Inc., San Jose, CA), or quartz plates (665.000QS, HELMA, Paris, France) of the same size, previously cleaned for $1 \mathrm{~h}$ in a 1:1 mixture of $\mathrm{CH}_{3} \mathrm{OH}$ and $\mathrm{HCl}$, then cleaned with a $\mathrm{H}_{2} \mathrm{SO}_{4}$ solution $(>1 \mathrm{~h})$, and rinsed extensively with ultrapure water. The buildup of multilayer films by the spray technology consisted in the sequential spraying of the polycation (COL) and of the polyanion (PSS) solutions perpendicularly to the substrate in vertical position to allow the drainage of the solution, using com- 
mercial paintbrushes (Airbrush 134) from SEDIP (Poncarré, France) equipped with two-component nozzles with a diameter of $0.3 \mathrm{~mm}$ and operated at an air pressure of 1 bar. Each polyelectrolyte solution (COL or PSS) was sprayed onto the substrate surface for $5 \mathrm{~s}$. After a rest time of $15 \mathrm{~s}$, we rinsed with Milli-Qwater for $5 \mathrm{~s}$. Finally, after a further rest time of $15 \mathrm{~s}$, the deposition of the next polyelectrolyte layer followed the same sequence. Thereby, the deposition of a layer pair was achieved in $60 \mathrm{~s}$. The obtained film is denoted (COL/PSS) ${ }_{n}$ after the deposition of $n$ COL/PSS pairs of layers.

Transmission Electron Microscopy. The particle size of the inorganic crystals in films at various stages of growth was determined by transmission electron microscopy (TEM, Philips CM200) while their crystalline structure was studied by electron diffraction (ED) operating the instrument in the low-dose mode at 200 $\mathrm{kV}$ accelerating voltage. Images were taken with a numerical camera (Gatan, Orius 1000). The resolution of this setup is about of $0.2 \mathrm{~nm}$.

Environmental Scanning Electron Microscopy. Side-views of the cross sections of the inorganic coatings were obtained by environmental scanning electron microscopy (ESEM, FEl Quanta 400) after appropriately cutting the corresponding coated glass substrate.

UV-Visible Spectroscopy. (UV-vis). UV-vis absorption spectra of inorganic layers were recorded on a Varian Cary 500 scan spectrometer on a quartz slides. The quartz slides were first cleaned with a $2 \%$ Hellmanex solution and then thoroughly rinsed with water. The polycrystallinity and sometimes the porosity of the films caused non-negligible light scattering and only allowed the monitoring of the absorbance up to a limited thickness of the coatings.

Acknowledgment. This work was supported by the project ANR06-BLAN-0197-01, "CartilSpray" from the Agence Nationale de la Recherche and the Fondation Avenir. G. Popa was supported by a doctoral fellowship of the Ministère de I'Enseignement Supérieur et de la Recherche. P. Zhao was supported by Sino-French Ph.D Institute Cooperation Program (2007). G. Decher is indebted to Institut Universitaire de France (IUF) for financial support. We thank E. Lancelot from Horiba Scientific (Villeneuve d'Ascq, France) for technical help concerning confocal Raman microspectroscopy.

Supporting Information Available: Table of solubility of investigated inorganic compounds, tables of observed and expected $d$ spacings of $\mathrm{CaF}_{2}, \alpha-\mathrm{C}_{2} \mathrm{CaO} \alpha$ and $\mathrm{Ca}_{5}\left(\mathrm{PO}_{4}\right)_{3}(\mathrm{OH})$ crystals, X-ray diffraction pattern of $\mathrm{CaHPO}_{4}$ obtained by spraying, top view scanning electron micrographs of films composed of $\mathrm{CaHPO}_{4}$ after 100 spray cycles and top view and side view scanning electron micrographs of films composed of $\mathrm{CaC}_{2} \mathrm{O}_{4}$ at various stages of film growth. This material is available free of charge via the Internet at http://pubs.acs.org.

\section{REFERENCES AND NOTES}

1. Venables, J. A.; Spiller, G. D. T.; Hanbucken, M. Nucleation and Growth of Thin-Films. Rep. Prog. Phys. 1984, 47, 399-459.

2. Zhang, Z. Y.; Lagally, M. G. Atomistic Processes in the Early Stages of Thin-Film Growth. Science 1997, 276, 377-383.

3. Barth, J. V.; Costantini, G.; Kern, K. Engineering Atomic and Molecular Nanostructures at Surfaces. Nature 2005, 437, 671-679.

4. Decher, G. Fuzzy Nanoassemblies: Toward Layered Polymeric Multicomposites. Science 1997, 277, 1232-1237.

5. Forrest, S. R. The Path to Ubiquitous and Low-Cost Organic Electronic Appliances on Plastic. Nature 2004, 428, 911-918.

6. Ozgur, U.; Alivov, Y. I.; Liu, C.; Teke, A.; Reshchikov, M. A.; Dogan, S.; Avrutin, V.; Cho, S. J.; Morkoc, H. A Comprehensive Review of $\mathrm{ZnO}$ Materials and Devices. J. Appl. Phys. 2005, 98, 041301.

7. Dawber, M.; Rabe, K. M.; Scott, J. F. Physics of Thin-Film Ferroelectric Oxides. Rev. Mod. Phys. 2005, 77, 1083-1130.

8. Chaneliere, C.; Autran, J. L.; Devine, R. A. B.; Balland, B.
Tantalum Pentoxide $\left(\mathrm{Ta}_{2} \mathrm{O}_{5}\right)$ Thin Films for Advanced Dielectric Applications. Mater. Sci. Eng., $R$ 1998, 22, 269-322.

9. Polman, A. Erbium Implanted Thin Film Photonic Materials. J. Appl. Phys. 1997, 82, 1-39.

10. Li, X. M.; Reinhoudt, D.; Crego-Calama, M. What Do We Need for a Superhydrophobic Surface? A Review on the Recent Progress in the Preparation of Superhydrophobic Surfaces. Chem. Soc. Rev. 2007, 36, 1529.

11. Klein, L. C. Sol-Gel Technology for Thin Films, Fibers, Preforms, Electronics, and Specialty Shapes; Noyes Publication: Park Ridge, NJ, 1988.

12. Attia, S. M.; Wang, J.; Wu, G. M.; Shen, J.; Ma, J. H. Review on Sol-Gel Derived Coatings: Process, Techniques and Optical Applications. J. Mater. Sci. Technol. 2002, 18, $211-$ 218.

13. Ichinose, I.; Senzu, H.; Kunitake, T. A Surface Sol-Gel Process of $\mathrm{TiO}_{2}$ and other Metal Oxide Films with Molecular Precision. Chem. Mater. 1997, 9, 1296-1298.

14. Patil, P. S. Versatility of Chemical Spray Pyrolysis Technique. Mater. Chem. Phys. 1999, 59, 185-198.

15. Nicolau, Y. F.; Menard, J. C. Solution Growth of ZnS, CdS, and $\mathrm{Zn}_{1-x} \mathrm{Cd}_{x} \mathrm{~S}$ Thin-Films by the Successive Ionic-Layer Adsorption and Reaction Process-Growth-Mechanism. J. Cryst. Growth. 1988, 92, 128-142.

16. Nicolau, Y. F. Solution Deposition of Thin Solid Compound Films by a Successive Ionic-Layer Adsorption and Reaction Process. Appl. Surf. Sci. 1985, 22-3, 1061-1074.

17. Nicolau, Y. F. Process and apparatus for the deposition on a substrate of a thin film of a compound containing at least one cationic constituent and at least one anionic constituent. Patent 4675207, 1987.

18. Decher, G.; Hong, J. D. Buildup of Ultrathin Multilayer Films by a Self-Assembly Process. 1. Consecutive Adsorption of Anionic and Cationic Bipolar Amphiphiles on Charged Surfaces. Makromol. Chem. Macromol. Symp. 1991, 46, 321-327.

19. Decher, G.; Schlenoff, J. B. Multilayer Thin Films: Sequential Assembly of Nanocomposite Materials; Wiley-VCH: Weinheim, Germany, 2003.

20. Ariga, K.; Hill, J. P.; Ji, Q. M. Layer-by-layer Assembly as a Versatile Bottom-up Nanofabrication Technique for Exploratory Research and Realistic Application. Phys. Chem. Chem. Phys. 2007, 9, 2319-2340.

21. Bertrand, P.; Jonas, A.; Laschewsky, A.; Legras, R. Ultrathin Polymer Coatings by Complexation of Polyelectrolytes at Interfaces: Suitable Materials, Structure and Properties. Macromol. Rapid Commun. 2000, 21, 319-348.

22. Decher, G. Layered Nanoarchitectures via Directed Assembly of Anionic and Cationic Molecules. In Comprehensive Supramolecular Chemistry; Sauvage, J.-P., Hosseini, M. W., Eds.; Templating, Self-Assembly and SelfOrganization, Vol. 9; Pergamon Press: Oxford, 1996; pp 507-528.

23. Decher, G.; Eckle, M.; Schmitt, J.; Struth, B. Layer-by-layer Assembled Multicomposite Films. Curr. Opin. Colloid Interface Sci. 1998, 3, 32-39.

24. Hammond, P. T. Recent Explorations in Electrostatic Multilayer Thin Film Assembly. Curr. Opin. Colloid Interface Sci. 2000, 4, 430-442.

25. Jessel, N.; Lavalle, P.; Ball, V.; Ogier, J.; Senger, B.; Picart, C.; Schaaf, P.; Voegel, J.-C.; Decher, G., Polyelectrolyte Multilayer Films - A General Approach to (Bio)-Functional Coatings. In Macromolecular Engineering; Gnanou, Y., Leibler, L., Matyiaszewski, K., Eds.; Elements of Macromolecular Structural Control, Vol. 2; Wiley-VCH: Weinheim, Germany, 2007; pp 1249-1306.

26. Johnston, A. P. R.; Cortez, C.; Angelatos, A. S.; Caruso, F. Layer-by-Layer Engineered Capsules and Their Applications. Curr. Opin. Colloid Interface Sci. 2006, 11, 203-209.

27. Tang, Z. Y.; Wang, Y.; Podsiadlo, P.; Kotov, N. A. Biomedical Applications of Layer-by-Layer Assembly: From Biomimetics to Tissue Engineering. Adv. Mater. 2006, 18, 3203-3224. 
28. Schlenoff, J. B.; Dubas, S. T.; Farhat, T. Sprayed

Polyelectrolyte Multilayers. Langmuir 2000, 16, 9968-9969.

29. Winterton, L.; Vogt, J.; Lally, J.; Stockinger, F. Coating of Polymers. Patent 9935520, 1999.

30. Izquierdo, A.; Ono, S. S.; Voegel, J.-C.; Schaaf, P.; Decher, G. Dipping versus Spraying: Exploring the Deposition Conditions for Speeding up Layer-by-Layer Assembly. Langmuir 2005, 21, 7558-7567.

31. Ostrander, J. W.; Mamedov, A. A.; Kotov, N. A. Two Modes of Linear Layer-by-Layer Growth of

Nanoparticle-Polylectrolyte Multilayers and Different Interactions in the Layer-by-Layer Deposition. J. Am. Chem. Soc. 2001, 123, 1101-1110.

32. Krogman, K. C.; Lowery, J. L.; Zacharia, N. S.; Rutledge,

G. C.; Hammond, P. T. Spraying Asymmetry into Functional Membranes Layer-by-Layer. Nat. Mater. 2009, 8, 512-518. 